\title{
WHATSAPP MESSENGER DALAM TINJAUAN MANFAAT DAN ADAB
}

\author{
Jumiatmoko \\ STIT Madina Sragen \\ jumiatmoko1391@gmail.com
}

This study aims to determine students' understanding regarding the benefits and Adab within the group using WhatsApp Messenger. This research uses descriptive quantitative approach. This research was conducted in Madina STIT Sragen with the subjects of the study were students of the $6^{\text {th }}$ grade with total of 11 responden. Data taken with a questionnaire and analyzed using descriptive statistics. The results showed that 1) WhatsApp Messenger is an Instant Messaging application that its use by internetbased student Madina STIT increased from three (3) years. 2) WhatsApp Messenger makes it easy to organize various academic community-based online virtual classroom system and multimedia features without limitations of time and space. 3) WhatsApp Messenger adaptable to its social culture including adab-adab in communicating without reducing the quantity, quality and modernity of the way of communication.

Keywords: WhatsApp, Benefits, Adab 
52 Jumiatmoko

\section{A. Pendahuluan}

Dewasa ini popularitas penggunaan WhatsApp Messenger atau akrab disebut WA di dunia Internasioanal maupun nasional meningkat tajam. ${ }^{1}$. WA merupakan teknologi Instant Messaging seperti SMS dengan berbantuan data internet berfitur pendukung yang lebih menarik. Aplikasi WhatsApp Messenger sangat potensial untuk dimanfaatkan sebagai alat pembelajaran. Pembelajaran di era digital sekarang ini sangat terbantu dengan kehadiran aplikasi WhatsApp Messenger. Pembelajaran pada perguruan tinggi menjadi salah satu obyek tumbuh suburnya penggunaan aplikasi WhatsApp Messenger ini.

Popularitas penggunaan aplikasi WhatsApp Messenger telah terjadi di kalangan civitas akademika Sekolah Tinggi Ilmu Tarbiyah (STIT) Madina Sragen. Survai menunjukkan, 90\% mahasiswa maupun dosen menggunakan aplikasi WhatsApp Messenger dalam kehidupan seharihari. ${ }^{2}$ maupun dalam kegiatan perkuliahan. WhatsApp Messenger memiliki berbagai fitur yang dapat digunakan untuk berkomunikasi dengan bantuan layanan internet. Fitur-fitur yang terdapat dalam Whatsapp yaitu Gallery untuk menambahkan foto, Contact untuk menyisipkan kontak, Camera untuk mengambil gambar, Audio untuk mengirim pesan suara, Maps untuk mengirimkan berbagai koordinat peta, bahkan Document untuk menyisipkan file berupa dokumen. Semua file tersebut dapat dalam sekejap dikirim melaui aplikasi gratis tersebut. Berbagai fitur tersebut tentu semakin menambah kemudahan dan kenyamanan berkomunikasi melalui media online.

Kemudahan dan kenyaman berkomunikasi ini tidak serta merta memberikan pemahaman yang baik bagi penggunanya mengenai manfaat dan adab atau dalam istilah dunia maya disebut Nettiquette. Nettiqutte dapat didefinisikan sebagai adab dalam ber-Social Media. Tingkat pemahaman mengenai manfaat dan adab menimbulkan berbagai macam dampak penggunaan aplikasi WhatsApp Messenger. Layanan yang paling banyak digunakan melalui aplikasi WhatsApp Messenger adalah percakapan kelompok atau Group Discussion. Grup WhatsApp Messenger merupakan sebuah layanan grup diskusi yang mampu menampung hingga 256 peserta. Jumlah yang sangat banyak dan dapat dikumpulkan hanya dalam satu aplikasi. Para anggotanya dapat saling berbagi diskusi dan informasi secara online ${ }^{3}$ melalui ruang virtual tersebut. Kurangnya pemahaman mengenai manfaat dan adab dalam grup WA justru akan menjadikan aplikasi yang super canggih ini membawa kemudharatan yang lebih banyak.

Mahasiswa STIT Madina Sragen merupakan salah satu dari sekian banyak pengguna WhatsApp Messenger Group baik dengan disertai dosen maupun sebatas sesama mahasiswa saja. Mereka merupakan bagian dari Nett Gen yang mengambil bagian pada era ini. Evans menyebut

1 Dan Bouhnik and Mor Deshen(2014) "WhatsApp Goes to School: Mobile Instant Messaging between Teachers and Students". Journal of Information Technology Education Research, Vol 13, hlm. 217-231

2 Survai terhadap mahasiswa STIT Madina Sragen pengguna WhatsApp Messenger Group, Kamis, 24 Maret 2016. Survai dilaksanakan dengan memberikan kuesioner kepada para mahasiswa yang menggunakan aplikasi WhatsApp Messenger. Dalam survai tersebut tidak dilaksanakan pemilihan sampel, tetapi seluruh populasi diikutsertakan.

3 Adhi Susilo (2014) Exploring Facebook and Whatsapp As Supporting Social Network Apllications For English Learning In Higher Education. Bandung: Widyatama, hlm.10 
Net Gen sebagai generasi yang hidup di era digital seperti ini. ${ }^{4}$ Sebagai pengguna WhatsApp Messenger Group mereka akrab dengan kehidupan diskusi ruang maya yang dihadirkan oleh aplikasi WhatsApp Messenger.

Sebagai bagaian dari civitas akademika perguruan tinggi Islam sudah seharusnya mereka paham mengenai norma dan etika atau adab dalam memilih serta menjalankan rutinitas berbagai aktivitas dalam ruang maya tersebut. Manfaat dari suatu kegiatan dan adab dalam melaksanakan kegiatan tentu harus dipegang teguh. Namun demikian, karena berbagai situasi dan faktor tidak menutup kemungkinan pula mereka mengingkari idealisme yang telah tertanam dan berakar pada diri mereka. Keraguan inilah yang kemudian mendorong harus adanya kajian mengenai bagaimana pemahaman mahasiswa STIT Madina Sragen mengenai WhatsApp Messenger Group dari segi manfaat dan adab.

\section{B. Perumusan masalah}

Berdasarkan latar belakang permasalahan tersebut maka dapat dirumuskan masalah sebagai berikut:

1. Bagaimana pemahaman mahasiswa tentang penggunaan WhatsApp Messenger Group?

2. Bagaimana pemahaman mahasiswa mengenai manfaat WhatsApp Messenger Group?

3. Bagaimana pemahaman mahasiswa mengenai Adab dalam berkomunikasi dalam WhatsApp Messenger Group?

\section{Tujuan Penelitian}

Sesuai dengan perumusan masalah tersebut maka tujuan penelitian ini sebagai dirumuskan sebagai berikut :

1. Mengetahui pemahaman mahasiswa tentang penggunaan WhatsApp Messenger Group?

2. Mengetahui pemahaman mahasiswa mengenai manfaat WhatsApp Messenger Group?

3. Mengetahui pemahaman mahasiswa mengenai Adab dalam berkomunikasi dalam WhatsApp Messenger Group?

\section{Manfaat Penelitian}

Penelitian ini memiliki manfaat utama sebagai referensi sekaligus perbaikan praktik penggunaan aplikasi WhatsApp Messenger Group bagi seluruh pengguna pada umumnya dan civitas akademika STIT Madina Sragen pada khususnya.

\section{E. Review Pustaka}

Review pustaka pada artikel ini menuangkan berbagai kajian literatur terhadap masingmasing variabel yang diikutsertakan dalam penelitian ini. Sebagai penunjang sekaligus penyeimbang kajian pustaka maka disertakan hasil penelitian penelitian-penelitain yang relevan.

4 Tony Evans (1995) “Globalisation, post-Fordism and open and distance education” Distance Education, Vol 16(2), hlm. 256-269. 
54 Jumiatmoko

\section{WhatsApp Messenger}

WhatsApp Messenger merupakan bagian dari sosial media. Sosial media merupakan aplikasi berbasis internet yang memungkinkan setiap penggunanya dapat saling berbagi berbagai macam konten sesuai dengan fitur pendukungnya. ${ }^{5}$ WhatsApp Messenger merupakan teknologi popular yang sangat potensial untuk dimanfaatkan sebagai alat pembelajaran. ${ }^{6} \mathrm{Al}$ Saleem menambahkan bahwa dalam WhatsApp Messenger terdapat Whatsapp Group yang mampu membangun sebuah pembelajaran yang menyenangkan terkait berbagai topik diskusi yang diberikan oleh pengajar. ${ }^{7}$

Keberadaan WhatsApp Messenger tidak terlepas dari keberadaan Net Gen atau generasi digital yang selalu menginginkan adanya pemutakhiran berbagai teknologi berbasis internet. Data empiris terkini dari Jafe dan Zane menunjukkan bahwa Net Gen memiliki kecederungan belajar secara kolaboratif, tidak memiliki respon yang baik terhadap cara pembelajaran ceramah, menginginkan informasi yang dapat mereka terima secara individu, dan senantiasa mengingikan berbagai macam materi pemebelajaran yang dapat diakses dengan mudah melalui piranti teknologi. ${ }^{8}$

\section{Manfaat Grup WhatsApp Messenger}

Pemutakhiran teknologi dimaksudkan perolehan manfaat yang lebih besar. Grup WA memiliki manfaat pedagogis, sosial, dan teknologi. Aplikasi ini memberikan dukungan dalam pelaksanaan pembelajaran secara online. Grup WA memungkinkan para penggunanya untuk menyampaikan pengumuman tertentu, berbagi ide dan sumber pembelajaran, serta mendukung terjadinya diskusi secara online. ${ }^{9}$ Rembe dan Bere mengungkapkan bahwa aplikasi Whatsapp Messenger dirasakan telah mampu meningkatakan partisipasi peserta didik, mempercepat terjadinya kelompok belajar dalam membangun dan mengembangkan ilmu pengetahuan. ${ }^{10}$ Tidak hanya itu, pembelajaran dengan bantuan aplikasi online seperti WhatsApp Messenger dapat meningkatkan kolaborasi dalam pembelajaran, berbagi pengetahuan dan informasi yang berguna dalam proses pembelajaran ${ }^{11}$, dan mempertahankan kesenangan pembelajaran sepanjang masa. ${ }^{12}$

5 Ennoch Sindang (2013) Manfaat Media Sosial dalam Ranah Pendidikan dan Pelatihan. Jakarta: Pusdiklat KNPK, hlm. 1

6 Bruce W Dearstyne (2011) "Smart phones: The new information revolution?" The Information Management Journal, vol. 39, hlm. 38-44.

7 Basma Issa Ahmad Alsaleem(2014) "The Effect of "WhatsApp" Electronic Dialogue Journaling on improving Writing Vocabulary Word Choice and Voice of EFL Undergraduate Saudi Students" Official Proceedings $21^{\text {st }}$ Century Academic Forum Conference at Harvard, Boston, MA U.S.A ISSN : 2330-1236, hlm.32-47

8 Feiertag Jeff and Zane, L. Berge (2008) "Training Generation N: how educators should approach the Net Generation”, Education + Training, Vol 50(6), hlm. 457-464.

9 Adhi Susilo (2014) Exploring Facebook and Whatsapp As Supporting Social Network Apllications For English Learning In Higher Education.Bandung: Widyatama, hlm.10

10 Patient Rambe \& Aaron Bere (2013) "Using mobile instant messaging to leverage learner participation and transform pedagogy at a South African University of Technology" British Journal of Educational Technology, Vol44(4), hlm. 544-561.

11 Avani Maniar and Aanal Modi (2014) "Educating Whatsapp Generation Through "Whatsapp", Zenith International Journal of Multidisciplinary Research. Vol 4 (8) August, hlm.23-38.

12 Yoany Beldarrain (2006) "Distance education trends: Integrating new technologies to foster student interaction and collaboration" Distance Education, Vol 27(2), hlm. 139-153. 
Parstisipasi, Kolaborasi, dan kesenangan belajar adalah nilai tambah bagi proses belajar.

Secara lengkap dan ringkas manfaat penggunaan Aplikasi Whatsapp Messenger Group dalam pembelajaran yaitu 1) Whatsapp Messenger Group memberikan fasilitas pembelajaran secara kolaboratif dan kolaboratif secara online antara guru dan siswa ataupun sesama siswa baik di rumah maupun di sekolah. 2) Whatsapp Messenger Group merupakan aplikasi gratis yang mudah digunakan. 3) Whatsapp Messenger Group dapat digunakan untuk berbagi komentar, tulisan, gambar, video, suara, dan dokumen. 4) Whatsapp Messenger Group memberikan kemudahan untuk menyebarluasakan pengumuman maupun mempublikasikan karyanya dalam grup. 5) Informasi dan pengetahuan dapat dengan mudah dibuat dan disebarluaskan melalui berbagai fitur Whatsapp Messenger Group. ${ }^{13}$

\section{Adab Komunikasi dalam WhatsApp Messenger Group}

Menelaah kemabali bahwa WhatsApp Messenger Group merupakan sebuah ruang kelas virtual yang memfasilitasi setiap anggotanya dapat berkomunikasi antara anggota satu dengan anggota lainnya. Jika dalam sebuah grup terdiri dari dosen dan mahasiswa maka perlu memperhatikan etika atau adab dalam berkomunikasi di dalamnya. Salah adab perbuatan menghormati guru adalah tidak berbicara kecuali atas izinnya, tidak banyak berbicara disebelahnya dan tidak menanyakan sesuatu yang membosankan. ${ }^{14}$ Menyela pembicaraan yang sedang disampaikan oleh seorang guru maupun membicarakan hal lain yang tidak sesuai dengan pembicaraan guru menjadikan seorang siswa kehilangan adab yang luhur kepada gurunya. Kelancangan dan ketidakpantasan tutur menjadi salah satu perusak etika yang harus dihindarkan. Termasuk seperti yang disampaikan Majid, tidak mengada-ada dalam bertanya. ${ }^{15}$

Etika dalam percakapan di dunia maya adalah dengan berkomunikasi dengan sopan. Cara berkomunikasi yang sopan dalam percakapan dunia maya adalah dengan mengirim tulisan yang sopan. ${ }^{16}$ Tulisan-tulisan, baik yang diterjemahkan sebagai tulisan yang sesungguhnya maupun konten percakapan lain yang didukung fitur aplikasi WhatsApp Messenger Group seperti gambar, video, dokumen, maupun suara harus dalam koridor tata aturan kesopanan. Semuanya itu akan mengindikasikan tingkat kesopanan cara berkomunikasi.

Kesopanan dalam berkomunikasi sangat relevan dengan keyakinan seorang muslim bahwa barangsiapa yang beriman kepada Allah dan hari akhir hendaknya Ia berbicara baik atau diam

${ }^{17}$ Kesopanan berarti menebar kebaikan, dan kebaikan dapat diraih melalui pintu kesopanan komunikasi. Baik dalam makna lain dapat pula dipahami penggunaan bahasa yang baik dan

13 Choki Barhomi (2015) “The Effectiveness of WhatsApp Mobile Learning Activities Guided by Activity Theory on Students' Knowledge Mangement” Contemporary Educational Technology, Vol 6 (3), hlm. 221-238 hlm.38

14 Ally As'ad (2007) Ta'limul Muta'alim (Bimbingan Bagi Penuntut Ilmu Pengetahuan). Kudus: Menara Kudus,

15 Majid Bin Su'ud al Usyan (2014) Adab-adab Berbicara (Adabul Kalam). Bandung: Permais UNPAD, h 12

16 Nur Hadi Waryanto (2006) "Etika Berkomunikasi di dunia Maya dengan Nettiquette" Makalah Seminar Nasional Matematika dan Pendidikan Matematika 2006 dengan tema "Trend Penelitian dan Pembelajaran Matematika di Era ICT" yang diselenggarakan pada tanggal 24 Nopember 2006.

17 Agus Waluyo (Ed) (2005) Hadist Arba'in An Nawawiyah Terjemah Bahasa Indonesia. Surabaya: AW Publisher, hlm.17 
benar sesuai budaya masyarakat Indonesia. Hal tersebut ditegaskan dan dikukuhkan agar siapapun yang terlibat di dalam WhatsApp Messenger Group merasakan kenyaman dalam bekerja secara kolaboratif dan kooperatif dalam kelompok mereka. ${ }^{18}$ Pengaruh luas yang bermula dari kenyamanan diisyaratkan oleh Yu, Tian, Vogel, dan Kwok terjadi pada peningkatan hubungan sosial antar anggotanya, harga diri, dan aktivitas belajar. ${ }^{19}$

Pada akhirnya agar budaya komunikasi online tetap dalam koridor positif maka harus disertai kecerdasan mental dan spritual ${ }^{20}$ Cara berkomunikasi dalam WhatsApp Messenger Group menunjukkan bagaimana kecerdasan metal dan spritual seseorang.

\section{F. Penelitian Relevan}

Dalam sebuah penelitian pendidikan, dengan judul "Using mobile instant messaging to leverage learner participation and transform pedagogy at a South African University of Technology". Menyimpulkan bahkwa WhatsApp meningkatkan akses informasi, efektivitas pembelajaran kooperatif dan motivasi. ${ }^{21}$

Studi lainnya mengenai penggunaan WhatsApp dalam pembelajaran dapat dilihat pada hasil penelitian Scornavacca, Huff, dan Marshall yang berjudul "Mobile phones in the classroom: If you can't beat them, join them" membuktikan bahwa siswa yang tergabung dalam grup Intant Messaging, seperti WhatsApp memiliki kecederungan untuk bertanya dan berpartisipasi lebih banyak $^{22}$ Dengan kuantitas bertanya dan partisipasi yang lebih banyak dari seorang siswa memungkinkan terjadinya perputaran arus informasi dan pengetahuan yang lebih banyak.

Lebih lanjut penelitian dengan judul "Preservice teachers' perceptions of instant messaging in two educational contexts" meneliti tentang bagaimana persepsi guru dan siswa dalam komunikasi via Instant Messaging. Hasilnya menunjukkan bahwa komunikasi via Instant Messaging tidak menjadi penghalang komunikasi yang luwes antara guru dan siswa ${ }^{23}$ meskipun ada etika yang harus tetap dipertahankan.

Ketiga penelitian tersebut di atas membuktikan bahwa penggunaan aplikasi Instant Messaging (IM) termasuk WhatsApp Messenger mampu mempercepat terbangunnya proses pembelajaran yang kooperatif dan kolaboratif. Proses pembelajaran yang kaya akan diskusi dan Shared Information tanpa kehilanganan keluwesan dan batasan etika atau adab yang disepakati lingkungan masing-masing.

18 Alfred P Rovai(2002) “Development of an instrument to measure classroom community” Internet and Higher Education, Vol 5, hlm. 197-211.

19 Angela Yan Yu, Stella Wen Tian, Douglas Vogel \& Ron Chi-Wai Kwok. (2010) "Can learning be virtually boosted? An investigation of online social networking impacts” Computers \& Education, Vol 55(4), h. 1494-1503.

20 Nuruddin (2012) Pengantar Komunikasi Massa. Jakarta : Rajawali Press, hlm.57

21 Aaron Bere (2013).”Using mobile instant messaging to leverage learner participation and transform pedagogy at a South African University of Technology". British Journal of Educational Technology, Vol 44(4), hlm. 544-561.

22 Eusebio Scornavacca, Sid Huff \& Stephen Marshall (2009) "Mobile phones in the classroom: If you can't beat them, join them" Communications of the ACM, Vol 52(4), hlm. 142-146.

23 Aaron Doering, Cynthia Lewis, George Veletsianos, and Kristen Nichols-Besel (2008) "Preservice teachers' perceptions of instant messaging in two educational contexts" Journal of Computing in Teacher Education, Vol 25(1), hlm. 5-12. 


\section{G. Metodologi Penelitian}

Penelitian ini difokuskan pada penggunaan Grup WhatsApp Messenger ditinjau dari segi manfaat beserta eksistensi adab yang meliputinya. Penelitian ini menggunakan rumusan masalah deskriptif. Berlandaskan pada perumusan masalah tersebut maka penelitian ini menggunakan pendekatan kuantitatif deskriptif. Pendekatan ini memaparkan data secara deskriptif sesuai temuan di lapangan. Penelitian ini menelaah dan menjawab pertanyaan mengenai keberadaan variabel mandiri bukan untuk mencari nilai hubungan antar variabel maupun perbandingan dengan sampel lainnya. ${ }^{24}$

Penelitian dilakukan pada populasi penelitian. Populasi penelitian ini adalah mahasiswa semester 6 STIT Madina Sragen tahun akademik 2015/2016 pengguna Grup WhatsApp Messenger yang berjumlah 11 Mahasiswa.

Analisis data yang digunakan dalam penelitian ini yaitu statistik deskriptif yang digunakan untuk mendeskripsikan atau menggambarkan data yang terkumpul sebagaimana adanya tanpa bermaksud membuat sebuah generalisasi. ${ }^{25}$ Bersesuaian dengan pengumpulan data dilakukan dengan Kuesioner. ${ }^{26}$

\section{H. Hasil dan Pembahasan}

Hasil penelitian dipaparkan ke dalam tiga bagian utama sesuai dengan rumusan masalah yang telah dirumuskan di atas.

\section{Penggunaan Aplikasi WhatsApp Messenger \\ a. Tahun Mulai Penggunaan WhatsApp Messenger}

Pembahasan hasil penelitian terkait dengan penggunaan WhatsApp Messenger diawali dengan paparan data mengenai tahun pertama penggunaan aplikasi WhatsApp Messenger oleh para responden. Tahun pertama yang dimaksud adalah permulaan waktu responden mulai menggunakan aplikasi WhatsApp Messenger. Data yang diperoleh menunjukkan seberapa lama para responden mengenal aplikasi WhatsApp Messenger tersebut.

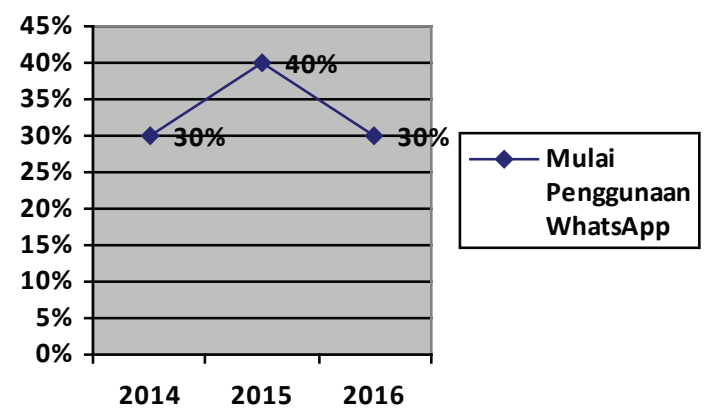

Gambar 1. Grafik Tahun Mulai Penggunaan WhatsApp Messenger

24 Sugiyono (2010) Metode Penelitian Pendidikan (Pendekatan Kuantitatif, Kualitatif, dan R\&D). Bandung: Alfabeta, hlm.56

25 Myrnawati Crie Handini (2012) Metodologi Penelitian untuk Pemula. Jakarta: FIP Press, hlm.21

26 Endang Mulayatiningsih (2013) Metode Penelitian Terapan Bidang Pendidikan. Bandung: Alfabeta, hlm.28 
Berdasarkan data yang tertuang dalam grafik di atas maka dapat diketahui bahwa responden mulai menggunakan aplikasi WhatsApp Messenger selama tiga (3) tahun terakhir. Jumlah yang mendominasi yakni di tahun 2015, sebanyak $40 \%$ para responden mulai menggunakan aplikasi WhatsApp Messenger. Data tersebut juga menunjukkan bahwa $70 \%$ responden merupakan pengguna yang sudah cukup lama menggunakan aplikasi tersebut, sedangkan $30 \%$ lainnya merupakan para pengguna baru.

\section{b. Durasi Penggunaan WhatsApp Messenger}

Setelah diketahui data tahun pertama penggunaan aplikasi WhatsApp Messenger, berikutnya dapat dicermati paparan data mengenai akumulasi durasi penggunaan aplikasi WhatsAppMessenger.
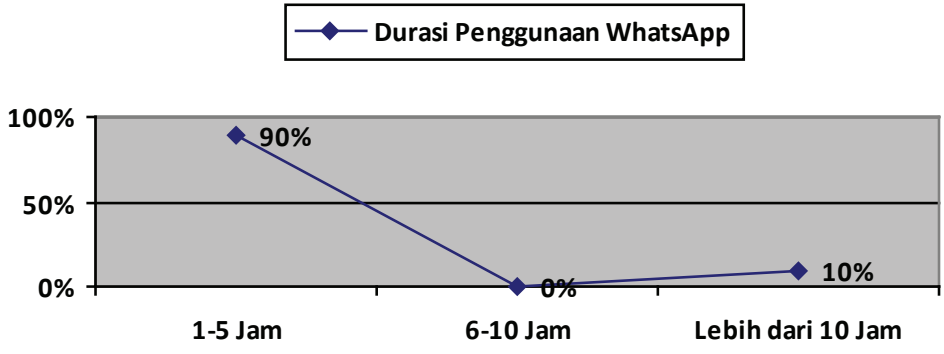

Gambar 2. Grafik Durasi Penggunaan WhatsApp Messenger

Data di atas menunjukkan bahwa sebanyak $90 \%$ responden menggunakan aplikasi WhatsApp Messenger, selama 1- 5 Jam, $0 \%$ menggunakan aplikasi WhatsApp Messenger selama 6-10\%, dan sisanya $10 \%$ menggunakan aplikasi WhatsApp Messenger selama lebih dari 10 Jam.

Dengan sudut pandang lain, dapat dinyatakan bahwa sebanyak $90 \%$ responden menggunakan aplikasi WhatsApp Messenger selama 2,5 hingga 12,5 menit setiap 1 jam. Sedangkan $10 \%$ lainnya menggunakan aplikasi WhatsApp Messenger selama minimal 25 menit dalam setiap 1 Jam.

\section{c. Pengetahuan kegunaan fitur WhatsApp Messenger}

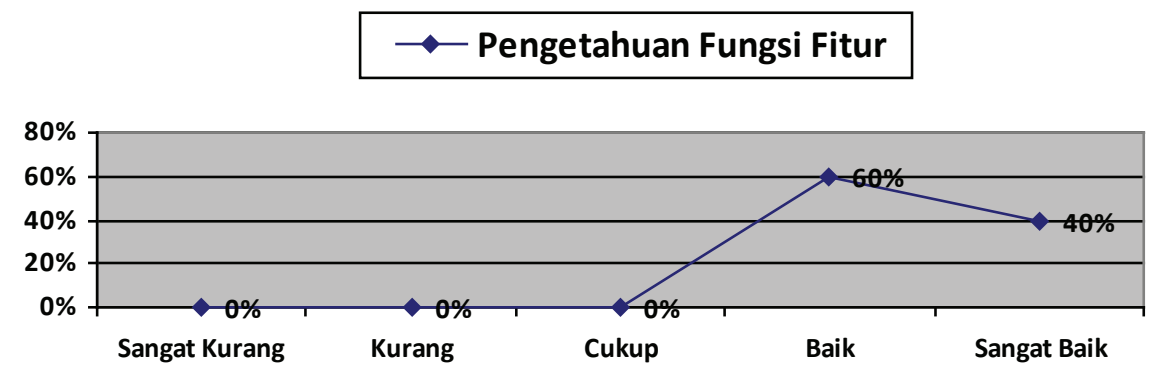

Gambar 3. Grafik Pengetahuan tentang Fungsi Fitur WhatsApp Messenger

Pengetahuan mengenai fungsi fitur pada WhatsApp Messenger baik bagi pengguna yang sudah cukup lama maupun baru berada pada taraf baik dan sangat baik. Hal ini menunjukkan bahwa Net Gen memiliki kemampuan beradaptasi dengan teknologi secara cepat. Pengetahuan yang baik mengenai fitur pada WhatsApp Messenger tentu saja menjadikan para responden 
mampu menggunakan aplikasi tersebut dengan baik.

Pada aspek pemahaman penggunaan Aplikasi WhatsApp Messenger dapat dinyatakan bahwa mayoritas responden telah mengenal aplikasi WhatsApp Messenger, selama satu (1) tahun dengan penggunaan selama 1-5 Jam per hari ditunjang pemahaman yang baik terhadap fitur-fiturnya.

\section{Pemahaman Manfaat WhatsApp Messenger}

Terkait dengan aspek pemahaman responden mengenai manfaat pada penggunaan aplikasi WhatsApp Messenger berikut ini disajikan beberapa data mengenai pemahaman manfaat aplikasi WhatsApp Messenger.

\section{a. Manfaat Grup WhatsApp Messenger dengan dosen}

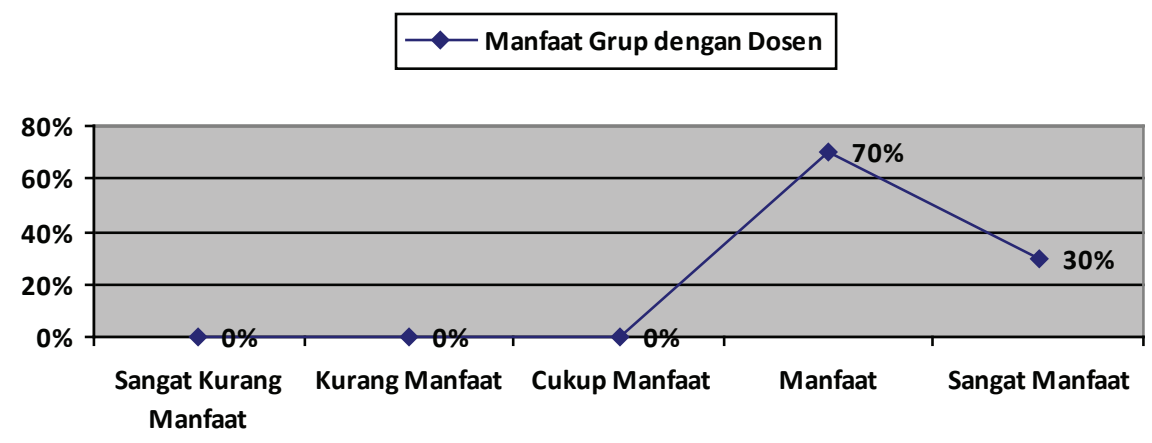

Gambar 4. Grafik Manfaat Grub WhatsApp Messenger dengan dosen

Grafik di atas menunjukkan bahwa $70 \%$ responden menyatakan bahwa grup WhatsApp Messenger dengan dosen dinilai bermanfaat dan $30 \%$ lainnya menyatakan sangat bermanfaat. Grup dengan dosen pada dasarnya merupakan grup atau kelompok diskusi yang mengikutsertakan mahasiswa dan dosen dalam satu chat room. Chat Room ini, berdasarkan data lapangan menunjukkan ruang virtual yang dinyatakan bermanfaat bagi mayoritas responden.

b. Aktivitas pemanfaatan Grup dengan dosen

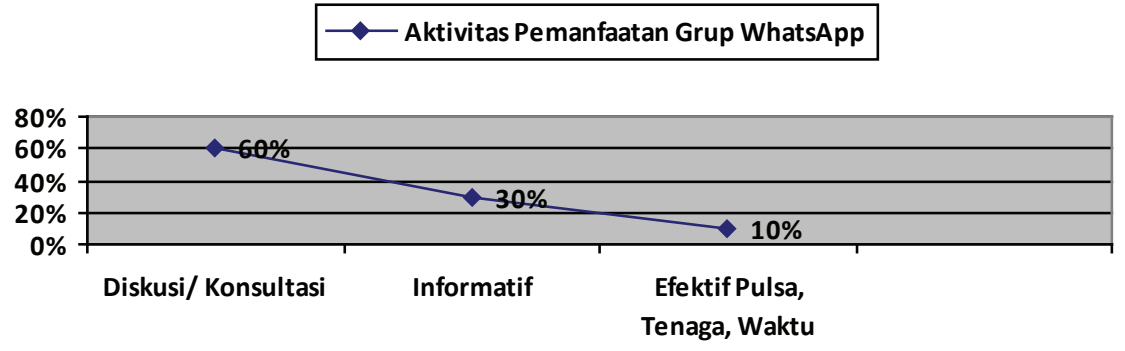

Gambar 5. Grafik Aktivitas pemanfaatan grup WhatsApp Messenger dengan dosen

Berdasar pada data di atas maka tiga (3) aktivitas utama yang dilakukan oleh responden dalam grup WhatsApp Messenger dengan dosen. Mayoritas responden, yakni sebanyak $60 \%$ memanfaatkan grup WhatsApp Messenger dengan dosen untuk berdiskusi atau berkonsultasi terkait suatu permasalahan yang terkait dengan perkuliahan. Grup WhatsApp Messenger 
$60 \mid$ Jumiatmoko

memberikan runag untuk saling bertukar informasi, hal ini disampaikan oleh $30 \%$ responden.

Manfaat ketiga yang disampaikan oleh $10 \%$ responden adalah WhatsApp Messenger menghemat pulsa karena yang digunakan adalah basis data internet, hemat tenaga karena tanpa harus pergi ke kampus dapat memperoleh informasi dari dosennya, dan hemat waktu karena cukup meluangkan 2,5 hingga 7,5 menit per Jam mereka sudah dapat berinteraksi serta memperoleh berbagai informasi. Keadaan yang demikian mampu menjadi peluang agar terjadinya percepatan pembelajaran. Zhu, Valke, dan Schellens membenarkannya bahwa agar terjadi percepatan pembelajaran perlu mengkombinasikan pembelajaran konvensional dan pembelajaran berbasis online ${ }^{27}$.

\section{c. Fitur Pendukung Aktivitas Akdemik}

Tersedia enam (6) fitur utama yang mendukung Group Chatting Room WhatsApp Messenger yaitu Document, Camera, Gallery, Audio, Maps, dan Contact. Terkait dengan aplikasi yang paling bermanfaat terhadap kegiatan akademik, berikut ini hasil pengolahan jawaban dari responden.

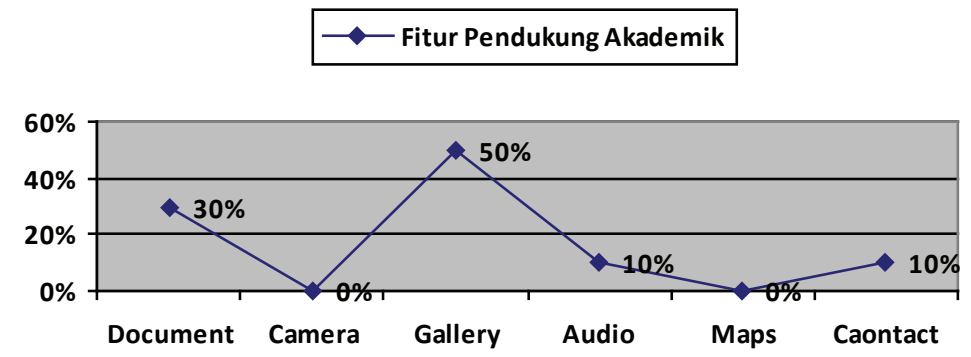

Gambar 6. Grafik Fitur WhatsApp Messenger pendukung kegiatan Akademik

Separuh (50\%) responden menyatakan bahwa fitur yang paling mendukung kegiatan akademik adalah Gallery. Gallery ini dapat digunakan untuk menyematkan kiriman berupa gambar ataupun video dalam Group Chatt Room. Sehingga bahan diskusi yang berupa gambar atau video dapat dibagikan secara cepat dan mudah melalui fitur ini.

Posisi kedua menempatkan Document sebagai fitur yang menunjukkan manfaat paling mendukung dalam kegiatan akademik bagi $30 \%$ responden. Fitur ini merupakan fitur yang baru pada aplikasi WhatsApp Messenger. Sebagai fitur baru, wajar bila belum banyak responden yang mengenal. Fitur ini tersedia bagi pengguna WhatsApp Messenger Indonesia mulai 2 Maret 2016. ${ }^{28}$ Fitur ini tersedia dengan cara user meng- up date aplikasi WhatsApp Messenger. Fitur ini, sesuai namanya, dapat difungsikan untuk menyematkan file dokumen. Namun, sementara ini file dokumen yang dapat dikirim hanya yang memiliki format pdf.

Mayoritas Responden menyatakan bahwa grup WhatsApp Messenger dengan dosen memberikan mafaat yang baik untuk berdiskusi dan menggali berbagai informasi terlebih dengan dukungan fitur-fitur WhatsApp Messenger utamanya Gallery dan Document.

27 Chang Zhu, Martin Valcke and Tammy Schellens (2009) "A Cross-Cultural Study of Online Collaborative Learning” Multicultural Education \& Technology Journal, Vol 3(1), hlm.33.

28 Fatimah Kartini Bohang (2016, 3 Maret). WhatsApp Sudah Bisa Kirim Dokumen, Begini Caranya, KOMPAS. tekno.kompas.com 


\section{Adab diskusi dalam Grup WhatsApp Messenger}

Data pertama pada bagian adab diskusi dalam grup WhatsApp Messenger menyajikan data perbandingan kenyamanan berdiskusi antara grup dengan dosen dan teman. Data ini menjadi acuan awal apakah adab yang harus ditunaikan mahasiswa kepada dosennya akan memberikan pengaruh pada kenyamanan berdiskusi dalam grup WhatsApp Messenger.

\section{a. Kenyamanan Berdiskusi}

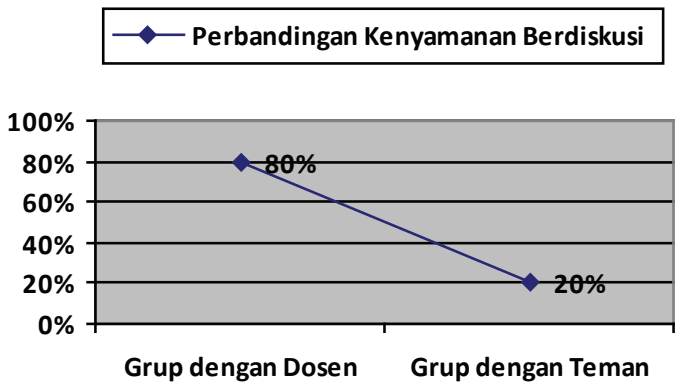

Gambar 7. Grafik Perbandingan Kenyamanan diskusi dalam grup WhatsApp Messenger

Sebanyak $80 \%$ responden menyatakan lebih nyaman berdiskusi dalam grup yang salah satu anggotanya adalah dosen mereka. Sedangkan sisanya $20 \%$ menyatakan lebih nyaman jika berdiskusi dalam grup yang anggotanya hanya teman-temannya saja. Sesuai dengan manfaat yang diperoleh dalam grup WhatsApp Messenger maka secara mayoritas mahasiswa lebih nyaman jika berdiskusi dalam grup yang terdapat dosen sebagai salah satu anggotanya.

Hal yang perlu diperhatikan yaitu bahwa dosen harus mampu menunjukkan antusiasmenya dalam berdiskusi. Sebab utamanya ialah antusiasme dosen dalam pembahasan sebuah topik akan menjadikan mahasiswa semakin antusias dan memahami pentingnya sebuah topik tersebut bagi mereka ${ }^{29}$

\section{b. Penggunaan Adab berdiskusi grup}

Seluruh responden sepakat bahwa dalam berdiskusi dalam grup dengan dosen mereka wajib menjaga adab. Penjelasan tersebut dapat disimak dalam grafik di bawah ini.

Penggunaan Adab

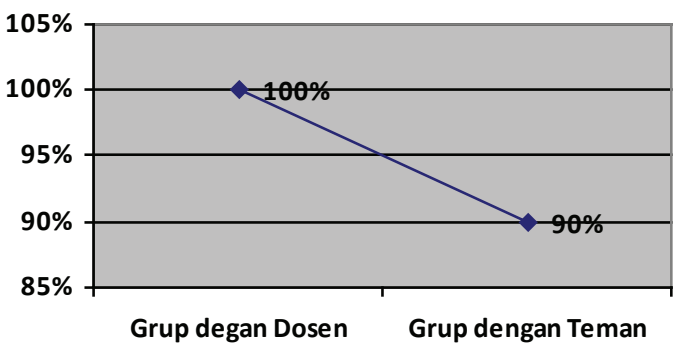

Gambar 8. Grafik Perbandingan Penggunaan Adab dalam grup WhatsApp Messenger

29 David Palmer (2007) "What Is the Best Way to Motivate Students in Science? "Teaching Science-The Journal of the Australian Science Teachers Association, Vol 53(1), hlm.38-42. 
Tidak seperti dalam grup dengan dosen, tidak seluruh mahasiswa, sebanyak $90 \%$ responden yang merasa perlu menjaga adab dalam komunikasi di dalam grup dengan teman.

Sebagai tokoh kunci maka kemampuan seorang dosen harus senantiasa dievaluasi dan ditingkatkan. Para dosen harus mampu mencapai peningkatan kualitas diri dan mampu mejadi contoh bagi mahasiswanya ${ }^{30}$. Contoh dalam menampilkan adab yang baik di ruang kelas yang sesungguhnya maupun kelas virtual dalam grup WhatsApp Messenger.

\section{c. Adab berdiskusi grup}

Penjabaran mengenai adab-adab yang penting untuk dipertahankan dalam diskusi pada grup WhatsApp Messenger dapat disimak dalam grafik analisis kuesioner berikut ini.

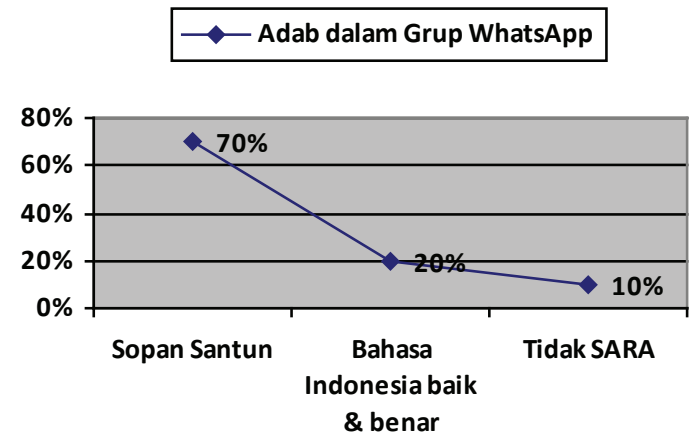

\section{Gambar 9. Grafik Adab dalam grup WhatsApp Messenger}

Sopan santun dalam menuliskan komentar di ruang grup WhatsApp Messenger menjadi komponen adab berdiskusi yang dinyatakan harus dijaga oleh $70 \%$ responden. Sopan santun dari seluruh anggota grup akan meningkatkan terjalinnya hubungan baik. MacGrath menunjukkan sisi terpentingnya bahwa hubungan baik adalah ruhnya pendidikan. ${ }^{31}$ Cara terbaik untuk membangun hubungan yang baik adalah memulai dengan berkomunikasi dengan baik, sopan santun contohnya.

Responden menyatakan adab selanjutnya yang harus di jaga adalah menggunakan bahasa Indonesia yang baik dan benar dalam menuliskan komentar di grup WhatsApp Messenger. Adab ini ditegaskan oleh $20 \%$ responden. Sisanya $10 \%$ responden menyatakan bahwa adabyang tidak kalah penting untuk dijaga adalah tidak menyampaikan unsur SARA dalam menyampaikan informasi maupun komentar di grup WhatsApp Messenger. Menjaga diri dari bersikap SARA akan menjaga keutuhan dan keharmonisan hubungan antar anggota grup, termasuk dosen dan mahasiswa. Hubungan yang baik antara dosen dan mahasiswa mampu membangun motivasi yang kuat bagi peserta didik ${ }^{32}$. Dengan demikian para mahasiswa sebenarnya pihak yang paling diuntungkan.

30 Nadir Celikoz (2010) "Basic Factors that Affect General Academic Motivation Levels of Candidate Preschool Teachers” Education, Vol 131(1), hlm.113-127.

31 Michelle MacGrath (2005) “Beyond Behaviour Management: Manage or Motivate?” Education Review, Vol 19(1), hlm. 57-64.

32 Tony Docan-Morgan and Valerie Manusov (2009) "Relational Turning Point Events and Their Outcomes in College Teacher-Student Relationships from Students' Perspectives” Communication Education, Vol 58(2), hlm. 155-188. 


\section{d. Keterlibatan dalam diskusi}

Secara alami manusia memiliki rasa ingin tahu yang tinggi dan serta kemampuan membuat suatu keputusan bahkan mencapai prestasi sesuai kemampuannya masing-masing. ${ }^{33}$ Kesemuannya itu akan berproses secara alami bila lingkungan disekitarnya memberikan kesempatan yang baik bagi pengembangan naluriah tersebut. Termasuk WhatsApp Messenger Group adalah lingkungan yang baik. Hal inilah yang kemudian terbukti dalam tanggapan para responden mengenai alasan mereka terkait aktivitas diskusi dalam grup WhatsApp Messenger. Berikut ini alasan keterlibatan mahasiswa dalam diskusi grup dengan dosen.

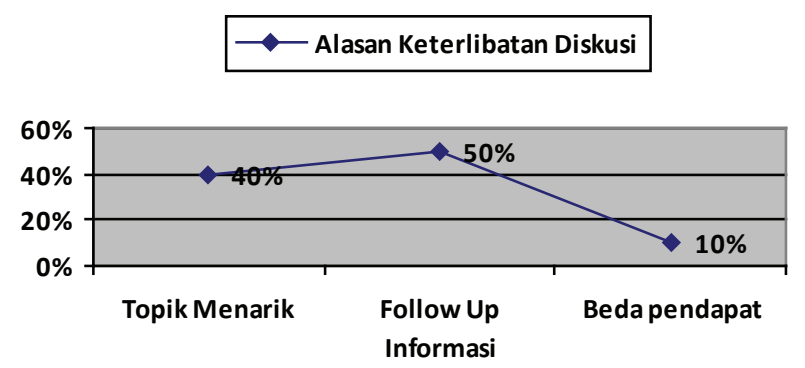

\section{Gambar 10. Grafik Alasan keterlibatan dalam grup WhatsApp Messenger}

Sebanyak $40 \%$ responden menyatakan bahwa mereka aktif terlibat dalam diskusi jika topiknya menarik. Separuhnya atau $50 \%$ menyatakan bahwa mereka tertarik mencari tahu lebih lanjut mengenai informasi yang dibagikan dalam grup. Yang paling sedikit, $10 \%$ nya responden menyatakan aktif berkomentar di grup jika ada pendapat yang tidak sesuai dengan sudut pandangnya.

Alasan-alasan tersebut menunjukkan bahwa adab yang harus dijaga tidak menjadi penghalang dalam aktivitas diskusi dalam grup WhatsApp Messenger dengan dosen. Dengan kata lain, keengganan untuk terlibat aktif dalam diskusi bukan karena responden harus menjaga adab dengan dosen, melainkan topik tidak menarik, informasi kurang penting, dan komentarkomentar yang ada sudah sama.

Fakta ini memberi celah kewajiban pada dosen bahwa dosen seharusnya semakin rajin memulai diskusi dengan topik menarik atau informasi yang bermanfaat atau setidaknya hanya sekadar memberikan sapaan hangat kepada anggota grup. Hasil Penelitian Legg dan Wilson menyimpulkan bahwa sapaan dari seorang dosen kepada mahasiswanya setiap pagi melalui email, pesan SMS, atau sosial media terbukti meningkakan motivasi belajar siswa. ${ }^{34}$

Pada bagian ini diperoleh titik temu bahwa adab komunikasi kepada dosen yang dijaga oleh responden dalam diskusi dalam grup WhatsApp Messenger tidak serta merta melemahkan aktivitas dalam diskusi itu sendiri. Topik yang menarik dan kebutuhan penemuhan akan rasa ingin tahu tetap menjadi jala persuasif untuk dibahas secara sopan dan santun bagi seluruh responden.

33 Dana Truby (2010) "What Really Motivates Kids" Instructor, Vol 119(4), hlm.26-29.

34 Angela M Legg and Janie H Wilson (2009) "E-Mail from Professor Enhances Student Motivation and Attitudes” Teaching of Psychology, Vol 36(3), hlm.205-211. 
$64 \mid$ Jumiatmoko

\section{Kesimpulan dan rekomendasi}

Hasil penelitian dan pembahasan di atas membuahkan simpulan dan rekomendasi yang ditujukan pada berbagai pihak. Tiga buah simpulan yang utama yaitu 1) WhatsApp Messenger merupakan aplikasi Instant Messaging berbasis internet yang penggunaanya meningkat sejak tiga (3) tahun terakhir. Peningkatan tersebut dibarengi dengan panjangnya durasi penggunaan dan cepatnya pemahaman penggunaan maupun fitur WhatsApp Messenger. 2) WhatsApp Messenger memberikan kesempatan bagi siapapun termasuk civitas akademika untuk menyelenggarakan berbagai kelas virtual berbasis online system dan fitur multimedia tanpa batasan ruang dan waktu. 3) WhatsApp Messenger adaptable terhadap budaya sosial penggunanya termasuk adab-adab dalam berkomunikasi tanpa mengurangi kuantitas, kualitas, dan modernitas cara berkomunikasi tersebut.

Berdasar kesimpulan tersebut maka WhatsApp Messenger Gruop dapat diajadikan sebagai inovasi pembelajaran bagi sekelompok peserta didik, sekelompok guru atau dosen dengan sekelompok peserta didik, Guru atau dosen dengan sekelompok peserta didik, maupun guru atau dosen dengan sekelompok orang tua peserta didik untuk saling terlibat dalam satu wadah untuk berdiskusi, berbagi informasi, atau hanya sekadar berbagi semangat belajar.

Sehingga akhirnya, WhatsApp Messenger merupakan aplikasi yang mampu menjangkau dimensi kemutakhiran, kemanfaatan, dan keadaban bagi akselarasi proses pendidikan di Indonesia umumnya dan STIT Madina Sragen khususnya yang harus senantiasa dibudidaya dan direkayasa sesuai kaidah-kaidah yang diyakini.

\section{Bibliografi}

As'ad, Ally (2007) Ta’limul Mutáalim (Bimbingan Bagi Penuntut Ilmu Pengetahuan). Kudus: Menara Kudus.

Barhomi, Choki(2015) "The Effectiveness of WhatsApp Mobile Learning Activities Guided by Activity Theory on Students' Knowledge Mangement" Contemporary Educational Technology, Vol 6 (3).

Beldarrain, Yoany (2006) "Distance education trends: Integrating new technologies to foster student interaction and collaboration" Distance Education, Vol 27(2).

Bere, Aaron (2013)."Using mobile instant messaging to leverage learner participation and transform pedagogy at a South African University of Technology”. British Journal of Educational Technology, Vol 44(4).

Bohang, Fatimah Kartini (2016, 3 Maret). WhatsApp Sudah Bisa Kirim Dokumen, Begini Caranya, KOMPAS. tekno.kompas.com 
Bouhnik, Dan and Mor Deshen (2014) "WhatsApp Goes to School : Mobile Instant Messaging between Teachers and Students". Journal of Information Technology Education Research, Vol 13.

Celikoz, Nadir (2010) "Basic Factors that Affect General Academic Motivation Levels of Candidate Preschool Teachers" Education, Vol 131(1).

Dearstyne, Bruce W (2011)"Smart phones: The new information revolution?” The Information Management Journal, vol. 39.

Docan-Morgan, Tony and Valerie Manusov (2009) "Relational Turning Point Events and Their Outcomes in College Teacher-Student Relationships from Students' Perspectives" Communication Education, Vol 58(2).

Doering, Aaron, Cynthia Lewis, George Veletsianos, and Kristen Nichols-Besel (2008) "Preservice teachers' perceptions of instant messaging in two educational contexts" Journal of Computing in Teacher Education, Vol 25(1).

Evans, Tony (1995) "Globalisation, post-Fordism and open and distance education" Distance Education, Vol 16(2).

Handini, Myrnawati Crie (2012) Metodologi Penelitian untuk Pemula. Jakarta: FIP Press.

Jeff, Feiertag and Zane, L. Berge (2008) “Training Generation N: how educators should approach the Net Generation", Education + Training, Vol 50(6).

Legg, Angela M and Janie H Wilson (2009) “E-Mail from Professor Enhances Student Motivation and Attitudes" Teaching of Psychology, Vol 36(3).

MacGrath, Michelle(2005) “Beyond Behaviour Management: Manage or Motivate?” Education Review, Vol 19(1).

Maniar, Avani and Aanal Modi (2014) "Educating Whatsapp Generation Through "Whatsapp”, Zenith International Journal of Multidisciplinary Research. Vol 4 (8) August.

Mulayatiningsih, Endang (2013) Metode Penelitian Terapan Bidang Pendidikan. Bandung: Alfabeta.

Nuruddin (2012) Pengantar Komunikasi Massa. Jakarta : Rajawali Press.

Palmer, David (2007) "What Is the Best Way to Motivate Students in Science? “ Teaching ScienceThe Journal of the Australian Science Teachers Association, Vol 53(1).

Rambe, Patient and Aaron Bere (2013) "Using mobile instant messaging to leverage learner participation and transform pedagogy at a South African University of Technology" British Journal of Educational Technology, Vol44(4).

Rovai, Alfred P(2002) "Development of an instrument to measure classroom community" Internet and Higher Education, Vol 5. 
66 Jumiatmoko

Saleem, Basma Issa Ahmad (2014) "The Effect of "WhatsApp” Electronic Dialogue Journaling on improving Writing Vocabulary Word Choice and Voice of EFL Undergraduate

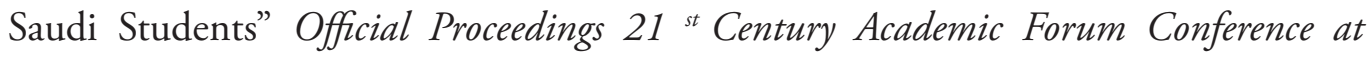
Harvard, Boston, MA U.S.A ISSN : 2330-1236.

Scornavacca, Eusebio, Sid Huff \& Stephen Marshall (2009) "Mobile phones in the classroom: If you can't beat them, join them" Communications of the ACM, Vol 52(4).

Sindang, Ennoch (2013) Manfaat Media Sosial dalam Ranah Pendidikan dan Pelatihan.Jakarta: Pusdiklat KNPK.

Sugiyono (2010) Metode Penelitian Pendidikan (Pendekatan Kuantitatif, Kualitatif, dan RఠD). Bandung: Alfabeta.

Susilo, Adhi (2014) Exploring Facebook and Whatsapp As Supporting Social Network Apllications For English Learning In Higher Education. Bandung: Widyatama.

Truby, Dana (2010) “What Really Motivates Kids" Instructor, Vol 119(4).

Usyan, Majid Bin Su'ud (2014) Adab-adab Berbicara (Adabul Kalam). Bandung : Permais UNPAD.

Waluyo, Agus (Ed) (2005) Hadist Arba'in An Nawawiyah Terjemah Bahasa Indonesia. Surabaya: AW Publisher.

Waryanto, Nur Hadi (2006) “Etika Berkomunikasi di dunia Maya dengan Nettiquette” Makalah Seminar Nasional Matematika dan Pendidikan Matematika 2006 dengan tema " Trend Penelitian dan Pembelajaran Matematika di Era ICT “ yang diselenggarakan pada tanggal 24 Nopember 2006

Yu, Angela Yan, Stella Wen Tian, Douglas Vogel \& Ron Chi-Wai Kwok. (2010) "Can learning be virtually boosted? An investigation of online social networking impacts" Computers \&Education, Vol 55(4).

Zhu, Chang, Martin Valcke and Tammy Schellens (2009) "A Cross-Cultural Study of Online Collaborative Learning” Multicultural Education \& Technology Journal, Vol 3(1). 